\title{
OS ANIMAIS DE ESTIMAÇÃO COMO MEMBROS DO AGRUPAMENTO FAMILIAR
}

\author{
PETS AS MEMBERS OF THE FAMILY GROUP
}

Recebido: 07.04.2020

Aprovado: 10.08 .2020

\author{
Germana Parente Neiva Belchior \\ Doutora em Direito pela Universidade Federal \\ de Santa Catarina. Professora do curso de \\ graduação e do Programa de Pós-Graduação em \\ Direito do Centro Universitário 7 de Setembro e \\ Auditora Fiscal Jurídica da Receita Estadual do \\ Ceará. \\ E-MAIL: germana_belchior@yahoo.com.br. \\ LATTES: http://lattes.cnpq.br/9420381711392213 \\ ORCID: https://orcid.org/0000-0003-1870-8958
}

\author{
Maria Ravely Martins Soares Dias \\ Mestra pelo Centro Universitário UNI7. \\ Advogada e professora. \\ E-MAIL: ravellymartins@gmail.com. \\ LATTES: http://lattes.cnpq.br/7239498699180483 \\ ORCID: https://orcid.org/0000-0001-5014-334X
}

RESUMO: A Constituição Federal de 1988 por meio do art. 226 não trouxe qualquer conceituação do que seria família e, ao mesmo passo, elucidou alguns modelos de entidades familiares. Apesar da inexistente definição, a Carta Maior de 1988 teve por preocupação reconhecer que o agrupamento familiar constitui base da sociedade e como tal carece de especial proteção do Estado. Neste sentido, o presente trabalho cinge-se em averiguar de que maneira os animais de estimação revelam-se como nova tendência do pluralismo familiar. A pesquisa tem por justificativa a necessidade de compreensão da ascensão da família e sua relação com os animais de estimação. Por sua vez, o objetivo da pesquisa é o de analisar de que maneira os animais de estimação tronaram-se membros do agrupamento familiar. A pesquisa foi realizada de forma qualitativa na medida em que analisou a família multiespécie enquanto fenômeno social e a interação entre animais humanos e não humanos até o ponto destes serem considerados como do grupo familiar, bem como foi utilizado o método indutivo em razão de buscar chegar a conclusões contrárias ao já positivado na norma jurídica. Por fim, a família passou por diversas transformações, admitindo em sua feição contemporânea o reconhecimento dos animais de estimação como membros, chegando assim a família multiespécie.

PALAVRAS-CHAVE: Família. Animais de estimação. Multiespécie.

ABSTRACT: The Federal Constitution of 1988 through art. 226 did not bring any conceptualization of what would be family and, at the same time, it elucidated some models of family entities. Despite the lack of definition, the Constitution of 1988 was concerned with recognizing that the family group constitutes the basis of society and as such lacks special protection by the State. In this sense, the present work is limited to find out how pets are revealed as a new trend of family pluralism. The research is justified by the need to understand the rise of the family and its relationship with pets. In turn, the objective of the research is to analyze how pets became members of the family group. The research was carried out in a qualitative way in that it analyzed the multispecies family as a social phenomenon and the interaction between human and non-human animals to the point that they are considered as part of the family group, as well as the inductive method was used because of seeking to arrive conclusions 
contrary to what has already been confirmed in the legal norm. Finally, the family underwent several transformations, admitting in its contemporary aspect the recognition of pets as members, thus reaching the multispecies family.

KEYWORDS: Family. Pets. Multispecies

SUMÁRIO: 1 Introdução 2 A ascensão do desenvolvimento jurídico e social das famílias contemporâneas e a heterogeneidade familiar 3 Animais humanos e não humanos e o surgimento da domesticação de animais 4 Os animais de estimação com nova tendência do pluralismo familiar 5 Conclusão 6 Referências

\section{Introdução}

A família mostra-se em constante transmudação ao passar dos tempos, modifica valores, pessoas e os integrantes dos núcleos familiares. Muita coisa muda no mundo, só não muda o intuito de formar família, formar até mesmo quando acreditam não existir.

Neste sentido, a família é importante para os que a compõem e mais ainda para o Estado, na medida em que aquela representa a célula mater da sociedade, ao passo que é núcleo estruturador das pessoas, conforme elucida o art. 226 da Constituição Federal de 1988.

Sob este aspecto, as famílias contemporâneas não representam somente núcleos formados por pessoas humanas. A evolução do conceito de família acabou por alargar o seu teor e vem trazendo para sua intimidade a presença de animais.

Diante disto tem-se como objeto central analisar de que maneira os animais de estimação revelam-se como nova tendência do pluralismo familiar. Para tanto, a abordagem acontecerá em três momentos distintos: análise da ascensão do desenvolvimento jurídico e social das famílias contemporâneas e a heterogeneidade familiar; a relação entre os animais humanos e não humanos e o surgimento da domesticação de animais; e, por fim, os animais de estimação e a família multiespécie como uma nova tendência do pluralismo familiar.

Justifica-se pela necessidade de compreensão da evolução da família e sua relação com a família multiespécie tendo em vista as novas formações de núcleos familiares, ausência de proteção e valorização e por fim, pela intromissão estatal na formação dos núcleos familiares desprestigiando, desta forma, entidades diferentes das impostas pela norma, numa visão hierarquizada e excludente.

No que tange a metodologia empregada, a pesquisa foi realizada de forma qualitativa na medida em que analisou a família multiespécie enquanto fenômeno social e a interação entre animais humanos e não humanos, dado o tempo, o local e seara cultural. Para efetivação, foi utilizado o uso de material bibliográfico e documental e o método indutivo em razão de buscar chegar a conclusões contrárias ao já positivado na norma jurídica, ou seja, a partir da análise do surgimento da família multiespécie como acontecimento social em relação a norma positivada por meio do estudo da legislação, do costume.

Por fim, o trabalho foi desenvolvido a partir da observância de três tópicos de desenvolvimento. Num primeiro momento foi feita a abordagem da evolução da família, desde seus primórdios a sua versão contemporânea chegando aos animais de estimação. Posteriormente, o segundo tópico analisou a interação entre humanos e animais, bem como o início da domesticação. E, finalmente, cuidou da percepção dos animais de estimação enquanto membro da família multiespécie, esta como tendência do pluralismo familiar. 


\section{A ascensão do desenvolvimento jurídico e social das famílias contemporâneas e a heterogeneidade familiar}

A família surge como noção inicial de agrupamento, especialmente o aglomerado humano. Sob o viés biológico, o fenômeno familiar ocorre como unidade de reprodução, tanto que a bíblia, em Gênesis, capítulo I, versículo 28, aduz: "frutificai e multiplicai-vos, e enchei a terra, e sujeitai-a; e dominai sobre os peixes do mar e sobre as aves dos céus, e sobre todo o animal que se move sobre a terra".

Em contrapartida, a família vista pela perspectiva social, proporciona a vida em associações e grupos, a originar diversas interações e estruturas, de modo a interessar, desta forma, à seara jurídica. Luiz Edson Fachin (1999) diz que a família, enquanto fenômeno sociológico, apresenta evolução desde à época da família patriarcal romana até a célula familiar da sociedade industrial contemporânea, mantendo estreita relação com as mutações impulsionadas pelos fenômenos sociais.

Sob este aspecto, importante frisar a origem etimológica da palavra família, conforme bem apontam, possui início na península italiana, mas precisamente da língua dos oscos e seu significado permeava a ideia de escravos ou servos de um mesmo patrão, frisando, desta forma, a ideia de agrupamento de pessoas (FARIAS; ROSENVALD,2012).

A família possui papel fundamental na vida dos seres humanos, pois dentro de seu âmbito é que irão acontecer os mais variados e importantes fatos da vida, a abarcar o nascimento até o fim do ciclo vital.

O agrupamento familiar proporciona para além de atividades naturais, como a fala, o comportamento e a estrutura psicológica, os desígnios culturais do indivíduo, na medida em que o seio cultural da família influenciará diretamente nas futuras escolhas da pessoa pertencente àquele grupo, como estilo de roupas, música, o caminho profissional a ser traçado, enfim, a família enquanto estrutura familiar pode influenciar o sucesso ou a ruína do membro que a compõe (FARIAS; ROSENVALD,2012).

O fenômeno familiar, portanto, promove mudanças e uma interdisciplinaridade entre as mais diversas relações, dentro e fora da família, a merecer destaque as palavras de Chynthia A. Sarti (1995, p. 40):

Essas mudanças correspondem a uma ação deliberada, no sentido de um projeto emancipador que instituiu novos padrões de comportamento, mas que só foi possível por mudanças, na realidade exterior à família, que afetaram de maneira decisiva esta esfera da vida social, transformando-a fatalmente. Acontece que a família não é uma totalidade homogênea, mas um universo de relações diferenciadas, e as mudanças atingem de modo diverso cada uma destas relações e cada uma das partes da relação.

Neste sentido, as mudanças ocorridas ao longo dos tempos no âmbito familiar ocorreram por uma verdadeira complexidade e transformações de fatores, tanto que não há como fixar unicamente um modelo familiar a ser seguido, mas sim a diversidade familiar existente diante dos movimentos sociais ocorridos a cada tempo dentro de uma linha do tempo.

Conforme expõe Luiz Edson Fachin (1999), a família, como fato cultural, precede o direito e está subentendida no sistema jurídico, de forma a representar bem mais do que fotos, quadros e convivência entre pessoas. No âmbito jurídico, não cabe a percepção tão somente pelo Direito de Família, pois não revelaria todo o seu alcance. Nas palavras do 
referido autor, "antecede, sucede e transcende o jurídico, a família como fato e fenômeno (FACHIN, 1999, p. 14)".

Assim, deixando para trás um pouco da origem da família frente à história, surgiu como primeiro mandamento universal perante a família a proibição do incesto (FARIAS; ROSENVALD, 2012) como espécie de lei com viés estritamente moral, que vigora até hoje perante as famílias.

O incesto remonta as relações sexuais entre determinados parentes, as quais a lei, por meio de uma norma mandamental, proíbe. Desta forma, o incesto não representa crime dentro do ordenamento jurídico, mas compõe uma norma de caráter proibitivo dentro do Direito Civil, quando, por exemplo, são impedidos de casar ou manter união estável, os parentes (ascendentes e descendentes) em linha reta infinita, como pais e filhos, bem como os colaterais até o terceiro grau, como irmãos, tios e sobrinhos.

Prosseguindo, o modelo patriarcal e hierarquizado de família foi o pioneiro a ser previsto dentro do Código Civil de 1916, este sob influência da revolução francesa, no final do século XVIII, bem como pelo domínio esmagador da religião, visto a ideia de casamento como única maneira de "purificar" as relações sexuais entre um homem e uma mulher (DIAS, 2017).

O modelo patriarcal e hierarquizado, desta forma, era marcado pela forte presença masculina como chefe do lar e da família, por meio da entidade familiar denominada casamento, o mais tradicional modelo de entidade familiar. A presença do patriarcado nas famílias fazia com que a figura masculina exercesse um verdadeiro poderio em relação à mulher e aos filhos, numa nítida relação amealhada ao proprietário de terras.

Frise-se, como exemplo a essa presença patriarcal, que sob a égide do Código Civil de 1916, só era ressaltada a personalidade do homem, seus direitos e obrigações perante a ordem civil. De modo contrário, era imposta à mulher a condição de relativamente incapaz aos atos da vida civil e somente se estivesse devidamente casada e enquanto subsistisse a sociedade conjugal, conforme determinava o art. $6^{\circ}$, inciso II do revogado código, de maneira que era vista como propriedade de seu marido, enaltecendo a importância ao homem, ao casamento e o menosprezo em relação à figura feminina.

À época, a cultura católica era vista como base da sociedade e perpassava a seara jurídica fortemente. Assim, por muito tempo, o casamento foi visto como único modelo legítimo de família aceito socialmente, bem como em razão de sua influência religiosa, era indissolúvel, de modo que a única maneira de se achar livre de um matrimônio era por meio de um doloroso e demorado processo de anulação (HIRONAKA, 2015).

O Estado só veio a regulamentar o casamento no ano de 1980 , denominando-o de casamento civil. Antes da referida regulamentação, os únicos documentos que existiam eram os registros paroquiais de casamento e batismo. No entanto, a regulamentação só serviu basicamente para transcrever os requisitos impostos pela igreja. De tanto rigor exigido, o casamento passou a ser considerado como instituição (DIAS, 2017).

Apesar de todas as regras impostas e o rigor exigido pelo Estado e a Igreja, as pessoas passaram a não mais manter o casamento, quando daí passou a surgir a figura do desquite, que nada mais era do que o instituto que autorizava o fim do casamento por meio da separação de corpos, mas não dissolvia o vínculo entre marido e mulher. Por esta razão, nenhum deles era autorizado a casar novamente. Da mesma maneira, surgiu a chamada separação, que sucedeu o desquite, havendo tão somente uma troca de palavras e nenhum efeito prático relevante.

A rigidez imposta à instituição casamentária também respingou na filiação à época, ou seja, quanto aos filhos era observada uma classificação a depender da relação mantida entre os pais. Assim, somente era reconhecida a condição de filho legítimo àquele 
concebido dentro da relação de casamento, ou seja, sendo o casamento legítimo, o filho também o era.

O ano de 1977 foi revolucionário no que diz respeito ao casamento, pois foi instituído o divórcio, por meio da Lei $n^{\circ} 6.515$, de 26 de dezembro de 1977. A Lei, apesar de inovadora, ainda carregava restrições àqueles que desejavam pôr fim ao matrimônio, pois para a concretização do divórcio era obrigatória a separação judicial, na tentativa constante de manter o casamento (FARIAS; ROSENVALD, 2012).

O advento da Constituição Federal de 1988 foi um verdadeiro divisor de águas no que tange ao divórcio, pois trouxe consigo a figura da separação de fato. A partir de um ano do acontecimento da separação de fato, era autorizado o divórcio, descartando, desta forma, a separação judicial. No ano de 2010, de outra banda, por meio da Emenda de no 66, o parágrafo $\S 60$, do art. 226 da Constituição Federal de 1988 passou a prever a possibilidade de o casamento civil ser dissolvido pelo divórcio diretamente, bastando para tanto a manifestação de vontade de um dos cônjuges, suprimindo qualquer prazo anterior de separação fática ou judicial (MADALENO,2019).

Tem-se, desta forma, o casamento como uma entidade familiar reconhecida pelo Estado, com previsão expressa constitucionalmente por meio de art. 226, §1으, bem como regulamentada toda sua ordem procedimental, como processo de habilitação, celebração, efeitos, regime patrimonial até o divórcio, que pode ser promovido por qualquer dos nubentes por ato volitivo sem qualquer motivação ou averiguação de culpa, além de ter o vínculo matrimonial totalmente dissolvido, podendo qualquer deles contrair casamento novamente.

Ao lado do casamento, figura uma entidade familiar que de igual forma passou por diversas modificações sociais e jurídicas, até permanecer como hoje se encontra. Trata-se da união estável que, em tempos longínquos, não era reconhecida como entidade familiar e ameaçava a existência das "famílias de bem" formadas pelo casamento (DIAS,2017).

De início, importante destacar que, diante do escorço histórico, a união livre se mostra anterior ao casamento, tendo em vista que as pessoas sempre procuravam umas às outras com o objetivo primordial de afastar a solidão. Desta forma, a união informal acabava acontecendo diante de fatos naturais da necessidade do ser humano de viver em agrupamento, bem como da necessidade de subsistência do grupo e da prole (MADALENO, 2019).

Perante o Código Civil de 1916, a união estável não possuía proteção estatal, pois não era reconhecida como família. Os casais que viviam nessa condição eram marginalizados, visto que, à época, somente o casamento era meio legítimo para constituir família, diante da forte pressão e força que Igreja exercia para este fim. Assim permaneceu até meados de 1944, quando surgiu o Decreto-lei no 7.036, de 10 novembro de 1944, que iniciou de forma tímida pequenos ganhos aos casais informais, reconhecendo ao concubino o direito ao recebimento de indenização em ocasião de acidente de trabalho ocorrido com seu convivente (DIAS, 2017).

A atual união estável antes era denominada de concubinato. "Etimologicamente, concubinato significa comunhão de leito. Origina-se da expressão latina cum (com), cubare (dormir), concubinatus, significando o estado de mancebia, a companhia de cama" (FARIAS; ROSENVALD, 2012, p.508).

Sob este aspecto, o concubinato era classificado em duas modalidades: concubinato puro e concubinato impuro. A primeira fazia menção àquelas pessoas que não possuíam qualquer fato impeditivo para o casamento e não casavam por pura opção. Em contrapartida, a segunda modalidade referia-se às pessoas que de fato possuíam algum impedimento para o casamento, como, por exemplo, as pessoas casadas, tendo em vista 
ser o Brasil um país monogâmico, de forma que somente se admite a relação entre duas pessoas, bem como reconhece como crime a bigamia, caracterizada pelo casamento de uma pessoa com outras duas ao mesmo tempo.

Neste percurso, foi editada a Súmula 380 do Supremo Tribunal Federal, a qual dispôs acerca da partilha do patrimônio entre os concubinos. Assim, a relação de concubinato, que porventura construísse algum patrimônio, seria dissolvida tal qual uma sociedade de fato, ou seja, no âmbito do direito das obrigações, bem como o patrimônio adquirido na sua constância seria partilhado mediante a prova do esforço comum.

Em 1988, após pequenos ganhos e grandes travessias, a união estável foi contemplada finalmente pela Constituição Federal, ao admitir e reconhecer a união informal entre homem e mulher, desprovida de qualquer solenidade ou formalidade. Neste momento, a união estável deixou de ser vista como concubinato, bem como deixou de ser comparada à sociedade de fato oriunda do direito obrigacional.

No mesmo sentido, surgiram leis infraconstitucionais, a fim de regulamentar a disposição constitucional sobre a relação de companheirismo. A primeira delas veio a ser a Lei $n^{\circ} 8.971$, de 1994, a qual disciplinou a possibilidade de alimentos e o direito à sucessão (herança) entre companheiros, desde que ambos fossem solteiros, viúvos ou divorciados, no entanto, tal união deveria ter no mínimo cinco anos ou a existência de filhos para reconhecimento e proteção estatal (MADALENO, 2019).

Dois anos depois, foi editada a Lei $n^{\circ} 9.278$, de 1996, com um grande diferencial em relação à anterior: aniquilou o prazo temporal para sua caracterização da união estável. Assim, a união livre seria reconhecida desde que fosse mediante convivência pública, contínua, duradoura, entre um homem e uma mulher, e com o objetivo de constituir família, este o principal elemento diferenciador entre união estável e um namoro longo (DIAS, 2017)

Após a lei acima citada, restou regulamentada a união estável como o concubinato puro, deixando de existir diferenciação entre este e o concubinato impuro. Desta forma, o concubinato puro passou a ser simplesmente a união estável e o concubinato impuro, ou seja, das pessoas impedidas de casar, passou a simplesmente concubinato, e este sim não é reconhecido como entidade familiar, muito menos carece de proteção estatal e, consequentemente, fica na seara obrigacional.

Seguindo com o surgimento do Código Civil de 2002, a união estável foi agraciada com capítulo próprio, tal qual o casamento, trazendo inúmeros efeitos em relação aos companheiros, como: proteção; reconhecimento; regime patrimonial próprio; presunção de colaboração recíproca; direitos e deveres; uso de sobrenome; estabelecimento de vínculos de afinidade com os parentes do outro; eventuais ações de reconhecimento e dissolução perante à vara de família; dentre outros.

Diante disto, deixou o casamento de existir solitariamente frente ao ordenamento jurídico, passando a coexistir a união estável, num viés totalmente distinto e eivado de informalidade, mas que, de igual forma, detentora de proteção e reconhecimento estatal, abrindo espaço, inclusive, para a formação de novos núcleos familiares.

Outro tipo de família que enfrentou uma longa trajetória, e ainda serve de base para o preconceito, são as chamadas famílias homoafetivas, ou seja, famílias formadas a partir da união entre duas pessoas do mesmo sexo.

O primeiro obstáculo enfrentado se encontra na própria legislação, tendo em vista que a redação positivada tacha que a união estável, ou o casamento, deve ser estabelecida entre duas pessoas, mas de sexos distintos, ou seja, entre homem e mulher, não abrangendo, desta forma, os casais homoafetivos. 
Neste viés, o legislador continua inerte acerca da modificação do termo padronizado "entre homem e mulher", ficando a cargo da jurisprudência cuidar do trato relativo ao reconhecimento e à proteção das famílias homoafetivas, tendo como fundamento principal o fato de não existir lei que impeça sua formação, bem como a não taxatividade do rol das famílias previstas no art. 226 da Constituição Federal de 1988.

Assim, por meio da Ação direta de Descumprimento de Preceito Fundamental no 132/2008 e da Ação Direta de Inconstitucionalidade no 4277/ 2009, que, em seu âmago, pediam a equiparação das uniões homoafetivas às uniões estáveis entre homem e mulher, foi julgado procedente o pedido, de modo a atribuir uma nova interpretação ao Código Civil de 2002.

Desta forma, passou o art. 1.723 a receber interpretação conforme a Constituição, ou seja, sem promover a exclusão de outros tipos de famílias, a leitura deve ser feita de forma ampla, abrangendo casais heterossexuais e homoafetivos. Outrossim, bem lembra Rolf Madaleno (2019), quando aduz que é vedado o descumprimento das decisões advindas do Supremo Tribunal Federal, sendo que tais decisões produzem efeitos vinculantes e eficácia contra todos os órgãos do Poder Judiciário e da Administração Pública direta e indireta, em todas as esferas.

Sob a perspectiva de famílias surgidas a partir de enlaces matrimoniais ou informais, não se pode deixar de fora as denominadas famílias reconstituídas, formadas diante da existência anterior de outras sequências familiares e filhos de relações anteriores. Assim, o novo casal que se forma junta, a um só tempo, experiências passadas e novas e, neste embalo, também é inserida a prole, daí o nome família reconstituída, pois se reconstitui a partir de elementos precedentes (FARIAS; ROSENVALD, 2012).

Têm-se ainda, ao lado das famílias formadas a partir da união ou casamento entre duas pessoas, as famílias monoparentais e as anaparentais, como formas legítimas de entidades familiares e protegidas pelo Estado.

A família monoparental é caracterizada pela presença de um só genitor, pai ou mãe, e os filhos dentro de um lar. Neste sentido, houve por parte do legislador a sensibilidade de reconhecer que são e continuam sendo famílias as mães ou pais solteiros; viúvos; divorciados; advindo da adoção; reprodução assistida, dentre outras possibilidades.

O enquadramento das famílias monoparentais encontra respaldo na própria Constituição Federal, no art. 226, $\S 4^{\circ}$, quando aduz que "entende-se, também, como entidade familiar a comunidade formada por qualquer dos pais e seus descendentes."

Há também as chamadas famílias anaparentais, as quais, por sua vez, se constituem diante de um modelo abrangente de família, no qual não possui qualquer embasamento no conteúdo sexual, formada basicamente pelos elos afetivos entre os componentes. Um exemplar perfeito sobre famílias anaparentais são aquelas formadas unicamente pela presença de irmãos, sem a presença de qualquer ascendente (MADALENO, 2019).

O Superior Tribunal de Justiça, no ano de 2010, julgou em sede de recurso especial de número 57.506/MG, 4a Turma, que o imóvel em que residiam duas irmãs solteiras constitui bem de família, sendo, portanto, impossível a penhora para satisfação de credores, demonstrando mais uma vez que a ideia de família transcende qualquer conotação sexual ou modelo tradicional, mas que viver em grupo e possuir afeto é o elemento primordial para a sua efetiva proteção.

Diante de todos esses núcleos familiares e de toda a sua ascensão social e jurídica, importa salientar que o grande triunfo se deu a partir da Constituição Federal de 1988, que não trouxe qualquer definição do que seria família, mas tão somente expressou que a família é base da sociedade e, por esta razão, merece especial proteção do Estado. Sendo a família considerada a base da sociedade, ela exerce, por seu turno, uma função social 
por atingir diretamente a formação da personalidade das pessoas, tendo em vista não ser a família um fim em si mesmo conforme expõem (GANGLIANO; PAMPLONA FILHO, 2011).

O fato de a Constituição Cidadã de 1988 ter expressado em seu texto unicamente as famílias matrimoniais, as informais e as anaparentais, não expulsa e muito menos cria obstáculos para a formação de outros núcleos familiares, como os mencionados acima. A feição do conceito atual de família deve ser atrelada à ideia de heterogeneidade familiar, justamente por ser incapaz de existir somente um modelo de família a ser reconhecido, devendo ser feito um verdadeiro trabalho inclusivo de promoção familiar.

Destaque-se, por oportuno, que toda evolução jurídica e social da família aniquilou o modelo tradicional; imperativo; hierarquizado;matrimonializado; patriarcal; heteroparental; biológico; de unidade de produção e reprodução; de desigualdade entre sexos; de categorização dos filhos; indissolúvel, em um modelo plural; heterogêneo; democrático; de unidade afetiva; de igualdade entre homens, mulheres e filhos; heteroparental e homoparental; e, por fim, dissolúvel (FARIAS; ROSENVALD, 2012).

Diante da toda evolução das famílias aqui apresentada, bem como da mutabilidade do meio social, o ato de viver em agrupamento vem trazendo outras formas de entidades, agora não mais entre humanos, mas sim, por meio da inserção dos animais de estimação nos lares e nas famílias. Importante, portanto, analisar o surgimento das relações entre animais humanos e não humanos, desde o início da domesticação até o ponto em que se encontram, ou seja, quando passam esses animais a serem membros de uma família.

\section{Animais humanos e não humanos e o surgimento da domesticação de animais}

Frente à linha de estudo traçada, mostra-se de extrema necessidade a análise acerca das relações entre animais humanos e não humanos até a ideia de domesticação dos animais e sua inserção no lar das famílias contemporâneas. Para isto, o presente tópico cuida inicialmente das vertentes do direito animal, proteção infraconstitucional e domesticação.

A relação entre animais e humanos remonta ao tempo das antigas civilizações, como se observa por meio da arte pré-histórica de desenhos em grutas e cavernas. Além do mais, os animais não humanos sempre foram enxergados como de classe inferior à humana, por serem irracionais e por terem como desiderato servir ao homem (BAETA, 2018).

Neste contexto, a criação de animais foi destinada à alimentação e ao trabalho em benefício do animal humano, principalmente no tocante à domesticação, no intuito servirem como caçadores, protetores, força e, em última análise, companhia. Sob este enfoque, a relação entre humano e animal vem calcada na forte exploração.

Deste modo, o ato de domesticar surgiu na pré-história, a fim de proporcionar a plantas e animais adaptação com características próprias e úteis para auxiliar a vida humana. Ademais, por força da domesticação, houve diversas modificações nas características originárias de plantas e animais, a fim de proporcionar ao homem a utilidade desejada. A palavra doméstico, portanto, advém do latim "domus" possuindo como significado o termo casa, ou seja, os animais nesta condição vivem segundo domínio do homem que perpassa gerações (OLIVEIRA ET AL, 2011).

Sobre o início da domesticação, estudos apontam que há alta probabilidade de os primeiros animais a serem domesticados terem sido os lobos asiáticos. Os lobos são antepassados dos cães domésticos, que hoje frequentam a maioria dos lares. Assim, calcula-se que o ato de domesticar animais remonta há 12.000 mil anos em países como China, na Ásia, e na América do Norte quando, efetivamente, o animal de estimação 
passou a fazer parte das famílias, apesar de, à época, não representarem o valor afetivo que hoje possuem (DIAMOND, 2013).

$\mathrm{O}$ ato de domesticar os animais acabou por influenciar no comportamento social, visto que, se num momento anterior os animais serviam basicamente para funções de guarda e caça, hoje alcançaram um patamar superior perante o homem, na medida em que se tornaram animais de companhia.

Ao se tornarem animais de companhia, passaram os domesticados a ganhar espécie de compaixão perante os humanos, bem como repercussão no meio social, na medida em que foram, aos poucos, sendo contemplados com leis de proteção, a fim de garantir o chamado bem-estar animal.

O termo bem-estar é utilizado de forma ampla, abrangendo animais humanos e não humanos. No entanto, para ser utilizada a referida expressão em relação aos animais não humanos, é que a acepção de bem-estar deve relacionar-se com a individualidade de cada animal e não algo genérico que pode ser proporcionado pelo animal humano (BROOM; MOLENTO, 2004).

Desta forma, a ética relacionada ao bem-estar animal é focada em proporcionar uma esperada qualidade de vida aos animais não humanos, apesar de não se conseguir precisar com certeza o que abarcaria essa qualidade de vida. Ademais, busca a referida teoria legitimar o uso dos animais para as mais variadas finalidades, como pesquisa, alimentação, entretenimento, companhia, dentre outros, sob a perspectiva de ser assegurado direito de não sofrimento ou de sofrimentos desnecessários. (MEDEIROS, 2013).

Sobre o termo "animais de companhia", por meio do Decreto $\mathrm{n}^{\circ} 13$, de 18 de fevereiro de 1993, foi lançada a Convenção Europeia para proteção dos animais de companhia, pautada principalmente na obrigação do homem em respeitar as criaturas vivas, tendo em vista a presença de laços particulares entre o homem e os animais de companhia. Também foi ressaltada a importância dos animais nos lares, sob a perspectiva de melhoria da qualidade de vida proporcionada aos seus donos (DIAS, 2018). Na oportunidade, o referido decreto define animal de companhia como "qualquer animal possuído ou destinado a ser possuído pelo homem, designadamente em sua casa, para seu entretenimento e enquanto companhia (art. $\left.1^{\circ}\right) . "$

Importante neste ponto buscar o estudo relacionado acerca da interação entre humanos e animais, tendo em vista procurar compreender para que e qual o sentido dos animais não humanos na vida dos animais humanos, bem como o grau de importância despendido a partir das correntes da ética ambiental.

$\mathrm{O}$ antropocentrismo possui origem greco-latina, da seguinte forma: anthopos, o homem; centrium, centrado. Ou seja, nesta corrente há o posicionamento do homem em posição central no universo, colocando os demais seres vivos integrantes do ecossistema em posição inferior, a fim de servirem as necessidades humanas. Tudo o que não for da espécie humana terá uma utilidade (SILVA; RECH, 2017).

Segundo os ensinamentos de Fernanda de Medeiros (2013), o antropocentrismo radical revela-se como aquele que atribui exacerbada importância aos animais humanos, classificando-os como de categoria especial, levando-se em consideração um valor notável, ao passo que as vidas não humanas mostram-se com pouco ou até mesmo sem nenhum valor, vistas como bens, propriedade ou fonte de subsídios para os animais humanos.

O antropocentrismo clássico, portanto, encontra-se na defesa do homem como ponto central do meio ambiente, na medida em que este serve tão somente para realizar 
os desejos humanos, implicando, assim, numa perspectiva utilitarista do meio ambiente (BELCHIOR, 2015).

O antropocentrismo radical possui embasamento teórico na afirmação de falta ou na inclinação de ausência de racionalidade dos animais não humanos, bem como considera que somente os animais humanos possuem valor moral a ser respeitado. Importante, ainda, frisar que para esta corrente não pode haver qualquer restrição para a independência criativa humana, podendo, desta forma, ocasionar uma ameaça à vida nãohumana.

Nesse viés, admitir que somente o homem é dotado da capacidade de pensar e agir, é conceber a ideia de que este humano permeia de forma solitária o ambiente do qual ele é integrante, aniquilando outras formas de vida e existência (MENESES;SILVA, 2016).

Ressalte-se que o antropocentrismo radical possui fundamentos na racionalidade radical. Esta, por sua vez, ocasionou supressões sociais, mais especificamente de minorias, tais como mulheres, negros, indígenas, justamente por afirmarem que as pessoas inseridas nessas categorias não possuíam racionalidade. Na mesma medida, hoje defendem que conforme as minorias citadas, animais, plantas e ecossistemas não possuem racionalidade e, portanto, não existem moralmente, não os considerando como de categoria que careça de proteção especial (MENESES;SILVA, 2016).

Seguindo, eis que surge o antropocentrismo moderado (também chamado de alargado), o qual apregoa o amparo ao meio ambiente, bem como aduz que os interesses humanos não precisam fazer oposição aos interesses dos animais não humanos, na medida em que permite até mesmo agenciar os interesses destes (MEDEIROS, 2013).

Impende frisar que muito embora o antropocentrismo moderado (alargado) possua essa perspectiva de proteção ao meio ambiente e de promoção, não deixa de ter como centro de preocupação a racionalidade, dita como privilégio somente dos animais humanos, colocando-os, desta forma, em posição de superioridade em relação aos animais não humanos.

Neste ponto, a Constituição Federal de 1988, mesmo trazendo um capítulo próprio em relação ao meio ambiente, o faz de maneira a servir o gênero humano, ou seja, que o homem continua sendo o objeto central de cuidado pelo direito, bem como que o meio ambiente natural deve ser preservado em razão das exigências dos animais humanos (SILVA; RECH, 2017).

No mesmo sentido, Benjamin (1999) afirma que o caráter antropocêntrico que serviu de base para o texto constitucional tem fundamento principal na tutela da saúde pública, pois esta não pode ser garantida se houver um meio ambiente deteriorado. Mais uma vez, demonstra-se que o destinatário das normas é a sociedade humana.

Todo esse modo de agir e pensar que norteia as correntes antropocêntricas trouxe incontáveis prejuízos naturais ocasionados pela ação do animal humano e despertou uma reação voltada à proteção e à preservação do meio natural, de modo a alterar, desta forma, a consciência da humanidade relativa a este ponto e a desenvolver o direito à proteção ambiental, o que fez surgir outras correntes filosóficas com esse viés protecionista, tais como: sensocentrismo, biocentrismo e ecocentrismo.

Segundo Fernanda de Medeiros (2013), o sensocentrismo possui uma ética dirigida aos animais não humanos e à consideração de valor. Aqui, todos, inclusive os animais não humanos, com certa consciência subjetiva, ou seja, que experimentam sensações como dor, sofrimento ou bem-estar, são considerados como seres sencientes e, portanto, devem ser igualmente considerados. 
Segundo Stelio Pacca Loureiro Luna (2008), a senciência se desdobra na capacidade de sentir, porém, mais ainda, estar consciente de si enquanto indivíduo, ou apenas do ambiente que o cerca. Ainda indica o autor que as evidências apontam que os animais sentem dor quando, por exemplo, evitam ou tentam fugir de estímulos dolorosos ou quando apresentam incapacidades físicas em decorrência da dor, e esta é melhorada ou curada por meio da administração de analgésicos.

Interessante ainda expor os comentários de Manoel Jacbsen Teixeira (2001), quando diz que, como parte do cotidiano, a dor é presente na vida de qualquer ser vivo e ainda mostra-se como condição de base para a sobrevivência. A dor ainda serve de alerta para que sejam estabelecidos procedimentos para defesa ou simplesmente fuga.

Geralmente, encontram-se nesta corrente os animais não humanos vertebrados, como mamíferos, aves, répteis, anfíbios e peixes, pois, como seres sencientes, possuem sistema nervoso central mais sofisticado e, consequentemente, provam de experiências dolorosas.

Em consonância, há a corrente biocêntrica que, tal qual o sensocentrismo, privilegia a senciência como valor, e ainda vai mais além, ao abranger, inclusive, outros seres e organismos vivos.

Inicialmente, o biocentrismo foi uma teoria pensada por Paul W. Taylor, com o intuito de abranger moralmente tudo aquilo que tiver vida. Assim, cada organismo vivo deve ser considerado como centro das coisas, bem como deve ser respeitada sua individualidade que o persegue (SILVA; RECH, 2017).

De acordo com a ética biocêntrica, segundo Medeiros (2013), o valor, a proteção moral e o direito à vida abarcam animais humanos, animais nãohumanos, plantas, organismos unicelulares, vírus e até bactérias. Há, portanto, a consideração do direito à vida a todos os seres vivos; todos são moralmente considerados.

A terceira corrente, denominada ecocentrismo ou fisiocentrismo, foi idealizada pelos estudiosos Aldo Leopold e Arne Naess. Segundo os autores, todas as formas vivas possuem valor único, e ainda ressaltam a importância da natureza a partir da perspectiva de que esta surgiu antes do homem e que este faz parte de sua composição (SILVA; RECH, 2017).

Comungando do mesmo pensamento, ressalta João Paulo Miranda (2016) que o ecocentrismo ou holismo reflete a percepção de igual respeito entre criaturas e ecossistema. Assim, há uma preocupação maior com a ecologia, visto a interação entre todos os seres no ecossistema.

Tal vertente leva em consideração o ecossistema como um todo, dentro de um pensamento filosófico voltado para a ecologia, ao apresentar valores na natureza em regime de igualdade entre seres com vida (bióticos) e seres sem vida (abióticos). A autora (MEDEIROS, 2013) ainda afirma que a corrente ecocêntrica associa-se ao holismo, ou seja, onde todos os seres interagem e compõem um todo, sendo impossível dissociá-los para compreendê-los de forma isolada.

Após a Revolução Francesa, ocorrida no século XVIII, os direitos humanos ganharam forma por meio da Declaração dos Direitos do Homem e do Cidadão, de 1789, de modo a remeter à conquista do chamado século das luzes, movido pelos ideais de igualdade, liberdade e fraternidade. Neste sentido, a Declaração dos Direitos do Homem e do Cidadão foi internacionalizada, sendo inclusive adotada pela Assembleia Geral das Nações Unidas de 1948 (DIAS, 2011).

Ao mesmo passo, em 27 de janeiro de 1978 (Bruxelas, Bélgica), foi proclamada, pela Organização das Nações Unidas para a Educação, Ciência e Cultura- UNESCO, a Declaração 
Universal dos Direitos dos Animais, apesar da controvérsia quanto ao local exato de sua proclamação (TINOCO; CORREIA, 2010).

A Declaração de Direito dos Animais foi proposta por Georges Heuse, SecretárioGeral do Centro Internacional de Experimentação de Biologia Humana. A escrita do texto, por sua vez, fora feita após vários encontros, de nível internacional, a fim de discutir e estabelecer diretrizes para o relacionamento entre animais humanos e nãohumanos, tomando por base, principalmente, uma frente igualitária quanto ao direito à vida (DIAS, 2011).

Importante lembrar que a Declaração Universal dos Direitos do Animal representa tão somente uma carta de intenções que foi subscrita pelo Brasil. Desta forma, apesar de assinada pelo país, o texto não possui a força de uma Lei, tendo em vista que é um documento de cunho internacional não aprovado pelo Poder Legislativo. Portanto, por não possuir a forma de um tratado e por não constar sanções quando de eventuais infrações, não possui a eficiência que se espera (SILVESTRE; LORENZONI; HIBNER, 2018).

Neste sentido, cumpre lembrar que a referida Declaração compõe questões de ordem ética e moral, sendo ausente de qualquer força normativa ou regulamentar (PORTO; PACCAGNELLA, 2017), mas, no entanto, revela-se, ao lado da Declaração de Direitos Humanos, como um direito supranacional, tendo em vista seu reconhecimento em âmbito internacional, o que pressupõe, frente aos seus signatários, o seu cumprimento e respeito.

Sob este aspecto, a Constituição Federal de 1988 dispõe, em seu art. 225, acerca de um meio ambiente ecologicamente equilibrado e de uso comum do povo, como forma de se efetivar a sadia qualidade de vida, cabendo a todos, inclusive ao Poder Público, a obrigação de preservá-lo e defendê-lo para presentes e futuras gerações. Como bem afirmam Carina Costa de Oliveira e Pedro Henrique Saad Messias de Souza (2018, p. 810), "[...] há uma interface entre os direitos humanos e a proteção ambiental. A interpretação do termo sadia qualidade de vida ainda é obscura e incerta, desconectada de critérios objetivos."

Ainda afirmam os autores acima citados que o direito à sadia qualidade de vida mostra-se como direito fundamental ligado aos direitos socioambientais, com a função precípua de garantir a dignidade humana por meio da proteção ambiental (OLIVEIRA; SOUZA, 2018).

Nesta linha, interessante notar os apontamentos de Patrick de Araújo Ayala (2018), ao afirmar que as normas destinadas a proteger o meio ambiente não são protetivas em si; elas primeiro cuidam da dignidade humana. Ademais, o autor ainda menciona que a proteção à natureza obriga desafios distintos e ocorre por meio da integridade ecológica, de modo que protegendo por primeiro a natureza é que se protegerá a dignidade.

O meio ambiente mostra-se como elemento condicionante à sadia qualidade de vida em seus mais variados aspectos e formas, bem como indispensável à dignidade da pessoa humana, por esta razão alcança o nível de direito fundamental (BELCHIOR; VIANA, 2017).

Segundo apontam Germana Parente Neiva Belchior e lasna Chaves Viana (2017), as Constituições contemporâneas passaram a considerar como direito fundamental o direito ao meio ambiente ecologicamente equilibrado como forma de promoção da dignidade humana e da vida. Tal fenômeno recebe o nome de Ecologização do Estado e do Direito, como forma de o meio ambiente ser inspiração a todos os demais direitos fundamentais.

Ao mesmo passo, no decorrer dos incisos do dispositivo constitucional acima citado, encontra-se, no que diz respeito à proteção dos animais não humanos, a previsão contida no inciso VII do parágrafo primeiro, quando informa que faz parte do dever de todos "proteger a fauna e a flora, vedadas, na forma da lei, as práticas que coloquem em risco 
sua função ecológica, provoquem a extinção de espécies ou submetam os animais a crueldade."

Nessa linha de raciocínio, afirma-se que os animais não humanos, por estarem contemplados nas tenazes do art. 225 da CF de 1988, são, igualmente, titulares de direitos fundamentais e que, por ser um direito fundamental, deveria limitar outro direito fundamental.

No que diz respeito aos direitos dos animais não humanos, cuida, especificamente, o inciso VII do parágrafo primeiro, acerca do foco de proteção à fauna e à flora, havendo inclusive a inibição de condutas que venham a ocasionar perigo à função ecológica, a provocar a extinção de espécies ou, ainda, que acarretem aos animais situações de crueldade.

Outrossim, mostra-se pertinente ressaltar a norma contida no parágrafo terceiro do mencionado caput, onde há previsão de possíveis sanções de ordem penal, administrativa, bem como o dever de reparar danos àqueles que, por meio de suas condutas, venham a lesionar o meio ambiente, e, por via de consequência, os animais nãohumanos.

Sobre o tema, George Marmelstein Lima (2016) aduz que, integralmente, as normas constitucionais produzem efeitos, umas mais outras menos, independentemente de regulação normativa, e, assim, não se poderia falar em omissão constitucional. No entanto, alguns desses efeitos, oriundos das normas constitucionais, só podem ser ou seriam mais bem produzidos caso existisse uma regulamentação normativa. Nestes casos, há a possibilidade de se argumentar sobre omissão constitucional, até mesmo no caso de normas que habitualmente são classificadas como de eficácia plena e aplicabilidade imediata.

Nessa linha, as normas constitucionais, dentre elas as relacionadas ao meio ambiente e aos animais não humanos, possuem cunho mandamental e, portanto, de respeitabilidade frente a todos. Mais ainda, é afirmar que por si, sem necessidade de qualquer outra, possui eficácia jurídica, tanto que as demais normas infraconstitucionais devem estabelecer suas regras em conformidade com a Constituição Federal de 1988.

Considerando, desta maneira, que todas as formas de vida são importantes e que possuem abrangência na Carta Magna de 1988 carecem, portanto, de proteção estatal. Sendo que a articulação de tais direitos é imperativa a todos, não se concretizando somente em relação aos humanos, mas, de igual forma, é extensiva aos animais, tendo em vista a proibição à extinção e, ainda, à crueldade.

Duas vertentes principais cuidam da defesa dos direitos dos animais: liberalismo e abolicionismo animal. A primeira, liderada por Peter Singer, e a segunda, por Tom Regan (DIAS, 2011).

O liberalismo defendido por Peter Singer aduz a libertação animal como caminho para a humanidade. Tomando por fundamento os ideais de justiça, o autor acredita na senciência animal e na possibilidade de igualdade de consideração de interesses entre os seres (DIAS, 2011).

A corrente defensora do liberalismo animal tem sua defesa baseada no princípio da igual consideração de interesses, mesmo que em determinadas situações impliquem em prejuízos ou redução dos direitos individualistas dos animais humanos (RODRIGUES, 2012).

Em seu embasamento, a primeira vertente se preocupa com o viés da sensibilidade dos animais não humanos, tendo em vista que estes experimentam sensações como frio, fome, medo, sofrimento e, até mesmo, inteligência. Outrossim, ainda abarca em seu bojo questões que envolvem respeito, o próprio bem-estar e a compaixão. Vislumbra-se, neste ponto, que a consideração ao animal não humano encontra-se presa a uma visão ética e não própria do Direito (RODRIGUES, 2012). 
Neste sentido, o bem-estar animal faz uso de dois fundamentos: o tratamento humanitário e a eliminação do sofrimento desnecessário (RODRIGUES, 2012). Assim, a proteção ao animal não humano fica condicionada a uma regulamentação, ou seja, autoriza o uso de animais não humanos, até para fins de exploração, desde que não haja sofrimento e seja garantido o bem-estar, pois o fim precípuo continua sendo a satisfação dos animais humanos e, por via de consequência, autoriza a apropriação e a consideração como objetos ou coisas, a exemplo, o uso da expressão 'abate humanitário', na qual regulamenta as regras próprias de sacrifício de animais não humanos por meio de procedimentos que os tornem insensíveis à dor e ao sofrimento no momento do abate para consumo dos animais humanos.

O pensador Tom Regan propaga que os animais não humanos são sujeitos de uma vida, preocupando-se de maneira latente com direitos fundamentais em relação aos seres, não podendo haver violação. Propaga-se, neste sentido, que tal quais os animais humanos, os animais não humanos são sujeitos de uma vida, possuindo, portanto, o direito a viver sem qualquer interferência (DIAS, 2011).

Neste sentido, mostram-se oportunas as palavras de Heron Santana (2004), no que diz respeito aos animais não humanos, quando afirma que a problemática gira em torno de se atribuir ou não direitos fundamentais básicos, tais como vida, igualdade, liberdade e até mesmo considerá-los ou não como propriedade.

No que tange ao viés principiológico constitucional de proteção animal, como bem leciona Tagore Trajano de Almeida Silva (2014), há a necessidade de apontar a distinção entre princípios e regras para que haja uma melhor compreensão sobre o tema.

Assim, têm-se as seguintes vertentes: a que considera o poder normativo da Constituição, considerando os dispositivos de ordem mandamental; outra que propaga a Constituição como Texto maior e supremo em relação a todo o ordenamento jurídico; e, por fim, aquela que vislumbra a possibilidade de interpretação de todo ordenamento jurídico a partir dos ditames constitucionais.

Sobre o assunto, ética e meio ambiente caminham juntos, na medida em que a crise ambiental contemporânea não se encontra na aniquilação dos recursos naturais, e sim na relação entre o animal humano e a natureza. Nessa linha, por ter racionalidade, o homem, por meio de suas condutas e da ética solidária, influencia gerações, constituindo-se como dever de solidariedade frente a outras formas de vida, diferente da humana, a fim de promover o equilíbrio ambiental (BELCHIOR, 2015).

Neste sentido, a partir do conteúdo da norma, tem-se que a proteção dos animais não humanos representa um direito e, ao mesmo tempo, um dever, pois a norma do caput do art. 225 elucida a garantia a todos, sem distinção, de um meio ambiente ecologicamente equilibrado e, no desenrolar de seus incisos, impera a norma protetiva, de forma a se esperar do Estado condutas ativas, a fim de defender os animais não humanos.

Nessa linha de raciocínio, percebe-se que ainda há possibilidade de proteção de um direito à vida para além dos animais humanos. É dizer que, se o legislador constituinte trouxe em seu texto a proibição à crueldade, bem como a extinção das espécies, o direito à vida se estende aos animais não humanos.

Noutro giro, o princípio da igualdade a ser estendido ao animal não humano comporta a ideia de antiespecismo, ou seja, a preocupação e o zelo para com os outros devem independer de como são ou da capacidade que possuem. Apregoa o antiespecismo a igualdade entre as espécies frente à ordem jurídica, sem que haja predileções ou valorações de uma espécie em relação a outra, bem como o combate às desigualdades existentes. (SILVA, 2014). 
As leis brasileiras ocupam-se em garantir ao animal não humano simplesmente à ideia de bem-estar como seres dotados de sensibilidade, ou seja, capazes de perceber sentimentos. Noutras palavras, o arcabouço infraconstitucional tem como objeto precípuo tutela referente à proibição de maus-tratos, no sentido de proporcionar aos mesmos o tal "tratamento humanitário", sem, na realidade, proteger a vida.

$\mathrm{Na}$ verdade, pode-se afirmar que o vasto aparato legislativo é direcionado à proteção dos animais não humanos como forma de garantir a proteção dos animais humanos, ou seja, como se os primeiros fossem objetos dos segundos, de modo a revelar o caráter antropocêntrico nas normas existentes.

Por fim, após a análise do estudo acerca das relações entre animais humanos e não humanos até a ideia de domesticação dos animais, sua inserção no lar das famílias contemporâneas, bem como da análise das correntes da ética ambiental, cuidar-se-á, no próximo tópico, sobre a relação entre animais e humanos, a partir da chamada família multiespécie, como forma de demonstrar até que ponto as famílias podem evoluir e inovar quanto à presença de seus membros.

\section{Os animais de estimação com nova tendência do pluralismo familiar}

Posterior à análise das relações estabelecidas entre humanos e animais, neste ponto, abordar-se-á a relação entre os animais de estimação e os seres humanos na família multiespécie sob o reflexo do pluralismo familiar.

À família não cabe mais um caráter homogêneo, mas sim um universo de relações distintas, afastando-se totalmente dos modelos tradicionalistas e patriarcalistas, inserindose nesse meio os animais de estimação, que representam, no mundo contemporâneo, essas relações distintas estabelecidas com o ser humano, no instante em que passam a assumir a condição de membros dentro de uma família, abandonando, portanto, o atributo de mero objeto.

Nessa linha é que não se pode negar a existência de uma pluralidade de famílias e seus mais variados fatores, que se adaptam aos anseios sociais pertinentes à cada época, em contraponto às famílias patriarcais, nas quais havia a preocupação excessiva com a reprodução e com o patrimônio, sendo os laços afetivos pouco importantes ou até mesmo inexistentes. Quanto a este ponto, seria estranho imaginar um animal como parte da família, quiçá, estes mesmos substituírem os filhos humanos.

Ainda sobre o tema, ao se tomar como premissa a mutabilidade constante do conceito do que a instituição da família apresenta, compreende-se esta pelas inúmeras possibilidades de manter as mais diversas relações, e a presença de amor e a distribuição de afeto, mas ao mesmo tempo apresenta elementos variantes, cada um correspondente a cada época de como vive a sociedade.

A família, portanto, deve possuir um caráter instrumental, ou seja, servir de instrumento para a promoção e o desenvolvimento da personalidade humana. Diante da instrumentalidade, chega-se à dignidade da pessoa humana, liberdade (autonomia privada), afetividade e felicidade, justamente por serem elementos componentes da família contemporânea (FARIAS; ROSENVAL, 2012).

Sobre o afeto presente nas relações, este ganhou importância diante das mutações familiares, na medida em que a percepção de família se dissociou do casamento. Passou o afeto a ser o elemento estruturante da formação das famílias contemporâneas, sendo a sua ausência motivo suficiente para dissolver qualquer núcleo familiar (MADALENO, 2019).

$\mathrm{O}$ afeto, portanto, cuida de ser o novo paradigma das famílias. Afirma-se que o afeto é um fato social e psicológico, sendo de extremo interesse ao mundo jurídico a sua 
exteriorização advinda das relações interpessoais. A exteriorização do afeto se traduz por meio da condutas objetivas, como o cuidados, responsabilidade, deveres, etc (PEREIRA, 2015)

Exemplificando a repercussão do afeto nas relações jurídico-familiares, tem-se a posse de estado de filho; o objetivo ou ânimo de constituir família; e a exigibilidade de deveres da autoridade parental (DIAS, 2017).

No primeiro caso, posse de estado de filho, basicamente é a expressão paterno-filial em que aquele que observa acredita tratar-se de pai/mãe e filho. É o trato, a fama e o nome que promovem a ideia de verdade real, ou seja, que aquela relação baseia-se por primeiro no vínculo biológico, quando na realidade revela uma relação paterno-filial advinda do afeto. É a máxima da expressão popularmente conhecida: "pai é quem cria".

A segunda situação está relacionada à constituição da entidade familiar informal, ou seja, união estável. Para além de todas as suas características, a principal delas é o ânimo de constituir família, ou seja, o casal que vive a união informal vive como se casados fossem, é a projeção da teoria da aparência com repercussão direta nas relações jurídicofamiliares. Ao olhar aquele casal, o observador não consegue afirmar com certeza se aquela relação vem da união estável ou do casamento.

Por último, a terceira circunstância autoriza a exigibilidade de deveres próprios da autoridade parental, na medida em que o pai/mãe afetivo exerce diante do filho afetivo em igualdade de condições os mesmos deveres decorrentes do poder familiar em relação ao pai/mãe biológico, sem qualquer mitigação.

Importante frisar que o afeto também proporcionou consequências até mesmo no âmbito penal, quando da análise da Lei Maria de Penha, Lei $n^{\circ} 11.340$ de 2006, ao aduzir, no inciso III do art. $5^{\circ}$, que figura como violência doméstica e familiar contra mulher aquela oriunda de "qualquer relação íntima de afeto, na qual o agressor conviva ou tenha convivido com a ofendida, independentemente de coabitação" (DIAS, 2017).

Neste contexto, vem ganhando um grau significativo de popularidade, a chamada "família multiespécie", que pode ser conceituada como aquela formada pela interação humano-animal dentro de um lar, onde os componentes humanos reconhecem os animais de estimação como verdadeiros membros da família.

Assim, torna-se imperioso destacar quais os elementos norteadores para empregar uma real definição do que seria a família multiespécie, afinal, o simples fato de ter um animal de estimação em casa parece não se demonstrar suficiente para classificá-lo como real membro da família. Outrossim, os elementos aqui apontados não formam um rol taxativo e/ou cumulativo, mas tão somente induz, de forma exemplificativa, características próprias de famílias constituídas por humanos e animais de estimação.

Primeiramente, deve-se mencionar a necessidade da presença de afeto na relação humano-animal, na medida em que deve ser aferido o grau de importância que aquele ser representa para a família. A exemplo, têm-se os constantes casos de desaparecimento de animais, nos quais os tutores, movidos pelo desespero, oferecem até mesmo recompensa, na maioria das vezes pecuniária, pela devolução do animal desaparecido. Outro fator que merece destaque é a preocupação com o estado de saúde dos animais de companhia, cujos tutores despendem quantias altas para a reabilitação da saúde do animal na tentativa de poupá-lo de sofrimento e da morte.

Continuando, pontua-se o estabelecimento de uma convivência constante entre os membros humanos e os animais de companhia, merecendo relevância a convivência dentro lar, visto que aqueles animais que vivem na área externa da casa, somada à falta de qualquer participação na rotina dos membros, bem como utilizados para outras funções, a exemplo da guarda, já descaracterizaria a formação de uma família multiespécie. Ademais, 
os animais verdadeiramente vistos como membros da família interagem constantemente com as pessoas moradoras do lar, interferindo na rotina de seus tutores (LIMA, 2015).

Ainda sobre a convivência, nota-se a preocupação dos tutores em incluir de todas as maneiras seus animais de companhia nas atividades desenvolvidas pela família, como viagens, fotos para os álbuns, compra de presentes, e, até mesmo, a realização de festa comemorativa pelo natalício do animal. Todas demonstram caráter inclusivo e reafirmam a condição do animal como membro da família (LIMA, 2015).

Além disso, a consideração moral seria outro indicativo para conceituar este novo arranjo familiar para retratar a existência da preocupação com as consequências que determinadas ações podem gerar para outrem (LIMA, 2015). Encaixa-se, neste ponto, a disposição de se abster de determinadas coisas ou situações em benefício do animal: como deixar de viajar; voltar cedo para casa para o animal não passar muito tempo só; evitar determinados produtos de limpeza em virtude de alergias; entre outras inúmeras situações próprias de cada família multiespécie.

Diante das considerações apontadas acima, vislumbra-se que a família não está adstrita unicamente ao afeto e à convivência entre seres humanos, mas, de igual forma, entre o vínculo estabelecido entre humanos e animais levados para o ambiente familiar, tidos como animais de companhia, sendo até mesmo considerados como membros da família.

O Direito de Família age diretamente na esfera de individualidade do individuo, de modo que a análise desse ramo de estudo deve partir das premissas constitucionais para garantir a tutela jurídica pretendida no âmbito existencial. Outrossim, a ingerência mínima do Estado nas relações familiares não deve ser compreendia como ausência do direito, mas sim como ambiente propicio a realização da promoção humana (TEPEDINO, 2015).

Desta maneira, o fundamental arrimo da família é a sua verdade contemporânea e nela corroboram as modificações culturais e sociais do tempo, para reconhecê-la em suas modificações evolutivas, nos seus valores emergentes, e por seus novos modelos que dimensionam sua feição plural e variável, proporcionando à comunidade jurídica a eterna missão de refletir e repensar sobre sua existência (ALVES, 2015).

Tem-se, diante da concepção atual da família, que sua principal característica é a pluralidade, na medida em que os novos modelos surgem sem a preocupação de se encaixar no sistema jurídico existente, ou seja, o organograma jurídico não consegue antever as sua formações, como o exemplo da formação da família multiespécie. Como núcleos de afeto, as famílias precisam ser reconhecidas e valozizadas independentemente de sua composição estrutural (DIAS, 2017).

A família multiespécie tem como característica principal a presença de um animal de estimação considerado como membro da família, na sua maioria, como filho para seus tutores. Esta condição vem justamente da presença do afeto na relação humano- animal. O animal de estimação, portanto, passa a ser filho do afeto, podendo, neste viés, ser estabelecida uma relação paterno-filial.

Sabe-se que diante da pluralidade e do afeto constante nas famílias contemporâneas, mostra-se discriminatória em relação aos mais diversos núcleos familiares categorizar ou até mesmo qualificar a condição dos filhos, não cabendo nem mesmo a expressão "filho biológico ou legítimo". Da mesma forma, deve ser entendido em relação à família multiespécie, pois os sentimentos de amor e cuidado também são cultivados na relação entre humano e animal.

O elemento da "vontade expressa" é o mais novo liame familiarparental, no plano civil. Esse significante tem sua precisão 
finalística, definindo outros vínculos que não meramente biológicos. De efeito, a família constitucional é emoção. É influência comportamental, é o desenvolvimento de cada um dos que a integram, tem o seu papel de valores especiais e morais que baseiam a sociedade (DIAS, 2017, p.33).

Desta forma, a autonomia da vontade expressa nas relações familiares as múltiplas possibilidades de formações familiares, de modo que, ao deixar os vínculos sanguineos de terem elevado grau de importância, o afeto se mostra como elemento identificador de vínculos, dentre eles aqueles relacionados ao animal de estimação no âmbito familiar.

Não cabe ao Estado categorizar ou expurgar do ordenamento jurídico a proteção jurídica que deve ser empregada às famílias multiespécies. Aqueles que vivem esta situação, vivem-na sob a condição da vontade de ali estarem, bem como do afeto.

O animal não humano assume a condição de filho na vida dos consortes familiares, ao acordar cumprimentar com primeiro "bom dia"; colocar a refeição; banhar; educar; preocupar-se quando ficam doentes; levar ao veterinário; proporcionar conforto; dar atenção; brincar; levar para passear; o medo de perder aquele ser extremamente dependente. Ser pai ou mãe vai muito além do ser ou não ser imposto pelo ordenamento jurídico, é sentir-se, todos os dias, responsável e amar incondicionalmente aquele ser, independentemente de ser uma pessoa ou um animal.

Segundo recente pesquisa liderada por Lissa Horn, da Universidade de Viena, na Áustria, divulgada pela revista Super Interessante (2016), cães enxergam seus tutores como se fossem seus pais. O experimento usou 22 (vinte e dois) cachorros divididos em grupos. $O$ teste revelou que os cães têm em seus donos uma segurança. $O$ sentimento assemelha-se à condição entre pais e filhos humanos pequenos.

Assim, mostra-se possível a relação entre os animais de estimação e os seres humanos na família multiespécie, esta como tendência do pluralismo familiar, tendo em vista a ascensão do animal dentro da família, ocupando a posição de membro e até mesmo filho em relação aos tutores.

O pluralismo familiar é a tendência da família contemporânea, pois autoriza as suas mais diversas formações, não cabendo ao Estado desqualificar ou desproteger os núcleos familiares que passam a desta maneira se estruturarem, pois se assim o for, haveria cabal violação do princípio articulado no art. 1.513 do Código Civil de 2002 quando aduz a proibição a qualquer pessoa, seja de direito público ou de direito privado, interferir na comunhão de vidas instituída pela família.

Por fim, afirma-se que a família multiespécie é tendência do pluralismo familiar, não cabendo ao Estado definir o que seria família e de que maneira deveria se compor, mas ao contrário, é dever seu abraçar e proporcionar proteção e valorização tendo em vista a liberdade de seus componentes, bem como a relevância social que o animal de estimação ganhou ao longo de sua trajetória.

\section{Conclusão}

As transmudações no contexto social e jurídico permitiram a formação de diversos núcleos familiares diferentes da entidade familiar constituída pelo casamento, que, à época do Código Civil de 1916, era reconhecida como única forma legítima para a formação da família. 
Com a Carta Política de 1988, começou a desconstrução da família patriarcal que era embasada principalmente no elo sanguineo e na presença do homem como único e titular ocupante do cargo de chefe da família, onde detinha a centralidade do poder.

Assim, com a mutabilidade do meio social, o ato de viver em agrupamento vem trazendo outras formas de entidades, agora não mais entre humanos, mas sim, por meio da inserção dos animais de estimação nos lares e nas famílias, dentro da ideia de liberdade e da cláusula aberta contida no art. 226 da Constituição Federal de 1988.

A partir das relações entre animais humanos e não humanos até a ideia de domesticação dos animais e de sua inserção no lar das famílias contemporâneas, bem como da análise das correntes da ética ambiental, tem-se que a Constituição Federal de 1988 por meio de seu art. 225 reconhece a proteção dos animais de forma imperativa, cabendo desta forma, ao reconhecimento de uma vida digna também aos animais, como parte de um ecossistema ecologicamente equilibrado.

Finalmente, o pluralismo familiar irradia-se como tendência da família contemporânea, pois autoriza as mais diversas formações familiares, não cabendo ao Estado desqualificar ou desproteger os núcleos que passam a integrar outros componentes que não sejam humanos, pois se assim o for, haveria cabal violação do princípio articulado no art. 1.513 do Código Civil de 2002 quando aduz a proibição a qualquer pessoa, seja de direito público ou de direito privado, interferir na comunhão de vidas instituída pela família.

\section{Referências}

ALVES, Jones Figueirêdo. Famílias pluralizadas: nova doutrina e experiência judiciária. Famílias nossas de cada dia. Coordenado por Rodrigo da Cunha Pereira. Belo Horizonte: IBDFAM, 2015.

BAETA, Rogério Farinha Silva Nunes. A teoria da libertação animal, bases, críticas e reais possibilidades após quatro décadas. Biodireito e direitos dos animais. Salvador, v. 27, p. 191-208, jun. 2018.

BELCHIOR, Germana Parente Neiva. Fundamentos epistemológicos do direito ambiental. Florianópolis: Lumen Juris, 2017.

BELCHIOR, Germana Parente Neiva; VIANA, lasna Chaves. Diálogos de complexidade e jurisprudência ambiental: estudo de caso sobre o princípio do mínimo existencial ecológico. Estado de Direito Ecológico: conceito, conteúdo e novas dimensões para a proteção da natureza. In (org): LEITE; José Rubens Moratto; DINNEBIER, Flávia França. São Paulo, 2017. p. 835-859.

BENJAMIN, Antônio Herman de Vasconcellos. Introdução ao Direito Ambiental Brasileiro . Revista de Direito Ambiental. n.14. São Paulo: RT, 1999.

BROOM, D.M ; MOLENTO, C.F.M. Bem-estar animal: conceito e questões relacionadas revisão. Archives of Veterinary Science v. 9, n. 2, p. 1-11, 2004. ISSN: 1517-784X. Disponível em: https://revistas.ufpr.br/veterinary/article/view/4057/3287. Acesso em: 06 de agosto de 2019.

DIAMOND, Jared. Armas, germes e aço. 15 ed. Rio de Janeiro: Editora Record, 2013. 
DIAS, Edna Cardoso. A fundamentalidade dos direitos dos animais no Estado de direitos e deveres. Fórum de Direito Urbano e Ambiental. São Paulo: Editora Fórum, 2011, p. 41-45. DIAS, Edna Cardoso. Os animais como sujeitos de direito. Jus Navigandi. Disponível em: <https://jus.com.br/artigos/7667/os-animais-como-sujeitos-de-direito>. Acesso em: 10 de dezembro de 2018.

DIAS, Maria Berenice. Filhos do afeto. 2. ed. São Paulo: Revista dos Tribunais, 2017.

DIAS, Maria Berenice. Manual de direito das famílias. 4.ed. São Paulo: Revista dos Tribunais, 2016.

DIAS, Maria Ravelly Martins Soares; BELCHIOR, Germana Parente Neiva. A guarda responsável dos animais de estimação na família multiespécie. Revista Brasileira de Direito Animal. v. 14. n. 2, p. 64-79, 2019. ISSN: 2317-4552. Disponível em: https://portalseer.ufba.br/index.php/RBDA/article/view/33325/19311. Acesso em: 03 de abril de 2020.

FACHIN, Luiz Edson. Elementos críticos do Direito de Família. Rio de Janeiro: Renovar, 1999.

FARIAS, Cristiano Chaves de; ROSENVALD, Nelson. Curso de Direito Civil: Direito das Famílias. 4 ed. Salvador: Ed. Juspodivm, 2012.

FARIAS, Cristiano Chaves de; ROSENVALD, Nelson. Curso de Direito Civil: parte geral e LINDB. 14a ed. Juspodivm: Salvador, 2016.

FARIAS, Cristiano Chaves. Direito Civil: volume único. 2. Ed. Salvador: Ed. Juspodivm, 2018.

FERNANDES, Bruno Marcelo Ferreira; SIMÃO FILHO, Adalberto. A importância do deveres fundamentais na consecução da sociedade atual. Revista Jurídica da Fa7. v.16. n.1. p. 1326, 2019. ISSN: 2447-9055. Disponível em: https://periodicos.uni7.edu.br/index.php/revistajuridica/article/view/581/736. Acesso em 02 de abril de 2020.

GANGLIANO, Pablo Stolze; PAMPLONA FILHO, Rodolfo. Direito de Família. 7.ed. São Paulo: Saraiva, 2011.

HIRONAKA, Giselda Maria Fernades Novaes. O conceito de família e sua organização jurídica. In: Tratado de direito das famílias[S.I: s.n.], p. 1023 il, 2015.

LIMA, George Marmelstein, . A eficácia incompleta das normas constitucionais: desfazendo um mal - entendido sobre o parâmetro normativo das omissões inconstitucionais. In: MALISKA, Marcos Augusto. Revista direitos fundamentais e democracia. Curitiba: 2016, p. 174-192.

LUNA, Stelio Pacca Loureiro. Dor, senciência e bem-estar em animais. Ciênc. vet. tróp., Recife-PE, v. 11, suplemento 1, p. 17-21 - abril, 2008. Disponível em: < http://rcvt.org.br/suplemento11/17-21.pdf>. Acesso em: 05 de agosto de 2019. 
MADALENO, Rolf. Direito de Família. 9. ed. Rio de Janeiro: Forense, 2019.

MADALENO, Rolf. O Direito de Família em Retrospectiva e em Expectativa. Revista Café e Justiça. Ano 7. Edição 10, 2019, p. 27

MEDEIROS, Fernanda Luiza Fontoura de. Direito dos animais. Porto Alegre: Livraria do Advogado Editora, 2013.

MENESES, Renato Carlos Cruz; SILVA, Tagore Trajano de Almeida. O especismo como argumento filosófico da não aceitação do animal como sujeito de direitos. Revista de Biodireito e Direitos dos Animais. Salvador: 2016, p. 218 - 234.

MIRANDA, João Paulo. A ética ambiental dos direitos humanos. JURIS, Rio Grande, v. 25: p. 141-164, 2016 Disponível em: https://periodicos.furg.br/juris/article/view/5996/4109. Acesso em: 05 de agosto de 2019.

OLIVEIRA, Carina Costa de; SOUZA; Pedro Henrique Saad Messias de. O direito à sadia qualidade de vida: contribuições da corte interamericana de direitos humanos às decisões do supremo tribunal federal. Estado de Direito Ecológico: conceito, conteúdo e novas dimensões para a proteção da natureza. In (org): LEITE; José Rubens Moratto; DINNEBIER, Flávia França. São Paulo, 2017. P. 809-834.

OLIVEIRA, Carina Costa de; SOUZA; Pedro Henrique Saad Messias de. O direito à sadia qualidade de vida: contribuições da corte interamericana de direitos humanos às decisões do supremo tribunal federal. Estado de Direito Ecológico: conceito, conteúdo e novas dimensões para a proteção da natureza. In (org): LEITE; José Rubens Moratto; DINNEBIER, Flávia França. São Paulo, 2017. P. 809-834.

PORTO, Adriane Célia de Souza Porto; PACCAGNELLA, Amanda Formisano. A verdadeira natureza jurídica da Declaração Universal dos Direitos dos Animais e sua força como carta de princípios. Âmbito Jurídico. Disponível em:http://www.ambitojuridico.com.br/site/?n_link=revista_artigos_leitura\&artigo_id=197 33. Acesso em: 28 de março de 2018.

SARTI, Cynthia. Família e individualidade: um problema moderno. In: CARVALHO, Maria do Carmo B. de, (Org.) A família contemporânea em debate. São Paulo: Cortez Editora, 1995.

SILVA, Diego Coimbra; RECH, Barcelos da.Adir Ubaldo. A superação do antropocentrismo: uma necessária reconfiguração da interface homem-natureza. R. Fac. Dir. UFG, v. 41, n.2, p.13-27,maio/ ago. 2017 ISSN 0101-7187. Disponível em:

<https://www.revistas.ufg.br/revfd/article/view/42609/24672>. Acesso em: 06 de agosto de 2019.

SILVA, Tagore Trajano de Almeida. Animais em Juízo. Programa de Pós- graduação em Direito da Faculdade de Direito da universidade Federal da Bahia. Salvador, 2009.

SILVA, Tagore Trajano de Almeida. Direito Animal e ensino jurídico: formação e autonomia de um saber pós-humanista. Salvador: Evolução, 2014. 
SILVA, Tagore Trajano de Almeida. Fundamentos do direito animal constitucional. Congresso Nacional do CONPEDI (18. : 2009 : São Paulo, SP) Anais do [Recurso eletrônico] / XVIII Congresso Nacional do CONPEDI. - Florianópolis : Fundação Boiteux, São Paulo, 2009. Disponível em: < https://s3.amazonaws.com/conpedi2/anteriores/XVIII+Congresso+Nacional+-+FMUS\%C3\%A3o+Paulo+(04\%2C+05\%2C+06+e+07+de+novembro+de+2009).pdf>. Acesso em: 05 jan. 2019.

SILVESTRE, Gilberto Fachetti; LORENZONI, Isabela Lyrio; HIBNER, Davi Amaral. A tutela jurídica material e processual da senciência animal no ordenamento jurídico brasileiro: análise da legislação e de decisões judiciais. Revista Brasileira de Direito Animal. SALVADOR, V.13, N. 01, PP. 55-95, Jan-Abr 2018.

TEIXEIRA, Manoel Jacobsen . Mecanismos de Ocorrência de Dor. Rev. Med. (São Paulo), 80(ed. esp. pt.1):22-62, 2001. Disponível em: < file://C:/Users/IFCE\%20Sobral/Google\%20Drive\%20(luizhernesto@gmail.com)/Ravelly\%2 OMartins\%20Advocacia\%20e\%20Assessoria\%20Jur\%C3\%ADdica/MESTRADO\%20UNI7/Mat erial\%20para\%20disserta\%C3\%A7\%C3\%A3o/Cap\%20I/63151-Texto\%20do\%20artigo82665-1-10-20131011.pdf>. Acesso em: 05 de agosto de 2019.

TEPEDINO, Gustavo. Dilemas do Afeto. Famílias nossas de cada dia. Coordenado por Rodrigo da Cunha Pereira. Belo Horizonte: IBDFAM, 2015.

TINOCO, Isis Alexandra Pincella; CORREIA, Mary Lúcia Andrade. Análise crítica sobre a declaração universal dos direitos dos animais. In: GORDILHO, Heron. Revista brasileira de direito animal. Salvador: 2010, p. 169- 195. 